\title{
Chronic Rhinosinusitis Patient with Nasal Polyp Characteristics at Otorhinolaryngology-Head and Neck Surgery Outpatient Clinic, Dr. Hasan Sadikin General Hospital, Bandung
}

\author{
Dina Riana, Arif Dermawan, Wijana, Ongka Muhammad Saifuddin \\ Department of Otorhinolaryngology-Head and Neck Surgery, Faculty of Medicine, Universitas Padjadjaran, Dr. \\ Hasan Sadikin General Hospital
}

\begin{abstract}
Objective: To evaluate chronic rhinosinusitis (CRS) with nasal polyp (NP) characteristics in patients with routine visits to the Otolaryngology-Head and Neck Surgery outpatient clinic of Dr. Hasan Sadikin General Hospital, Bandung.

Methods: This descriptive retrospective cross-sectional study was conducted at the Rhinology-Allergy Outpatient Clinic, Departement of OtolaryngologyHead and Neck Surgery, Dr. Hasan Sadikin General Hospital, Bandung, in the period of January 2014 to December 2014. Data were obtained from medical records and the sampling method used was total sampling. A total of 100 CRS with NP patients were evaluated. Nasal endoscopy examinations were performed. Patients were classified based on age into 10-20 years, 21-31 years, 32-42 years, 43-53 years, and $>54$ years groups.
\end{abstract}

Results: Chronic rhinosinusitis with NP incidences were mostly found in male patients compared to females. There were several CRS cases with NP risk factors, including smoking and allergy.

Received:

January 26, 2016

Conclusions: In the study, CRS with NP patients may possibly have one or more risk factors. Smoking is the major risk factor from CRS with NP after allergy.

Revised:

June 10, 2016

Keywords: Nasal polyp, nasal endoscopy, rhinosinusitis, risk factor [IJIHS. 2016;4(2):62-6]

Accepted:

August 3, 2016

pISSN: 2302-1381; eISSN: 2338-4506; http://dx.doi.org/10.15850/ijihs.v4n2.834

\section{Introduction}

Chronic rhinosinusitis (CRS) with nasal polyp (NP) is an inflamatory disorder that attacks paranasal sinus mucosal membrane of nasal mucosa which symptoms lasted more than 12 weeks. ${ }^{1,2}$ Chronic rhinosinusitis is a common heterogenous multifactorial disorder affecting children and adults. ${ }^{3}$ There are only a small number of studies that investigated CRS inflammations. In primary care as well as in epidemiological studies of CRS, the symptombased diagnosis is common, yet limited, because endoscopic and radiological signs are not considered. ${ }^{4}$

Correspondence:

Dina Riana, Department of Otorhinolaryngology-Head and Neck Surgery, Faculty of Medicine, Universitas

Padjadjaran, Dr. Hasan Sadikin General Hospital

Jl. Pasteur No. 38, Bandung, Indonesia

e-mail: d1na02@yahoo.com
Nasal polyps are defined as a chronic inflammatory disorder found in nasal mucosa and paranasal sinus mucosal membrane which is accompanied by edema symptom as well as inflammation of the nasal mucosa that swells into the nasal cavity. ${ }^{1,2}$ Chronic NP causes nasal congestion, mucous, olfactory disorder, headache, and decreased quality of life.

Nasal polyps affect around four percents of the population and are known to be associated with allergy, asthma, infection, cystic fibrosis, and aspirin sensitivity., ${ }^{5,6}$ The study also stated that NP presents with nasal obstruction, anosmia, rhinorrhoea, post nasal drip, as well as, less commonly, facial pain.

Recently, the terminology of rhinosinusitis is prefereably used than sinusitis. A study stated that sinusitis begins with rhinitis and rarely occurs without nasal inflammation. ${ }^{7}$

Chronic rhinosinusitis with NP becomes a disease with increasing incidences as well as 
increasing prevalences. ${ }^{2,8,9}$ In the United States, approximately 31 million people suffer from CRS. ${ }^{2,8}$ CRS that affects adults and children is usually associated with physical and emotional morbidity which causes economic impacts for some people.

Epidemiology data in Indonesia regarding to CRS prevalences have not been clearly studied. According to one study, Indonesian Ministry of Health, in 2003, published a report that nasal diseases and sinusitis were the $25^{\text {th }}$ of 50 serious diseases in which approximately 102,817 patients were recorded as suffering from NP in several hospitals. ${ }^{10}$ In addition, the study that was conducted at the Departement of Otolaryngology-Head and Neck Surgery of Cipto Mangunkusumo General Hospital Jakarta has also described that NP generally affects patients aged 30-50 years.

A similar study on CRS was also performed in another ares of Indonesia in 2008. A hundred and fourty two (75\%) patients with allergic rhinitis comorbidity of rhinosinusitis were recorded at the Rhinology-Allergy Outpatient Clinic, Departement of Otolaryngology-Head and Neck Surgery, Dr. Hasan Sadikin General Hospital, Bandung. ${ }^{11}$

The developments of integrated studies, that include pathophysiology, performance diagnosis, and disorder test for sinusitis have been concisely described in two expert recommendations from the United States and European. ${ }^{1,5,7,8}$ The United States experts, through a recommendation of Rinosinusitis Task Force (RSTF) in 1996 have recommended that rhinosinusitis should be diagnosed based on the clinical symptoms, symptom durations, physical examination, nasal endoscopy, as well as based on the computerized tomography (CT) scan. The European experts, through the recommendation of the European Position Paper on Rinosinusitis and Nasal Polyp (EPOS), has described the differences between NP and rinosinusitis that can be diagnosed through nasoendoscopy investigation.

Several studies on CRS were conducted but the major causal factors have not been clearly identified. Previous studies reported that there are several risk factors for CRS with NP i.e. sex, age, ethnic, occupation, asthma, allergic rhinitis, aspirin sensitivity, food allergy, smoking habit, genetic/family history, fungal or virus. . $^{3-8}$

This study investigated CRS with NP risk factors in patients who routinely visited the Otolaryngology-Head and Neck Surgery clinic, Dr. Hasan Sadikin General Hospital, Bandung based on medical history, physical test, and nasoendoscopy examination.

\section{Methods}

Descriptive and prospective methods were used in this study. The study was conducted at the Otolaryngology-Head and Neck Surgery clinic, Dr. Hasan Sadikin General Hospital, Bandung, in the period of January to December 2014. The subjects of the study were 100 medical records of CRS with NP patients. Total sampling was applied. Ethical approval for this study was obtained from the Health Research Ethic Commitee of Dr. Hasan Sadikin General Hospital.

The family history is primarily focused on asthma, aspirin sensitivity, nasal polyposis and atopy. ${ }^{7}$ In addition, The patients were asked several questions related to the habitual activities, including smoking habit.

The Lund-Mackay system of staging was used in this study to classify NP into 4 stages: stage 0 , no polyp; stage 1 , polyps in meatus media do not penetrate the nasal cavity when it is observed through anterior rhinoscopy examination but occurrence can be diagnosed through nasoendoscopy examination; stage 2 , polyps come out from the meatus media with swelling in the nasal cavity but does not obstruct the nasal cavity; stage 3, polyps obstruct the nasal cavity. ${ }^{12}$ The Lund-Mackay system of staging is considered a gold standard and mostly used in several previous studies.

Table 1 Subject Characteristics based on Sex, Age, and Polyp Stage

\begin{tabular}{lc}
\hline Subject Characteristics & Total \\
\hline Sex & \\
Males & $56(56 \%)$ \\
Females & $44(44 \%)$ \\
Age (years) & \\
$10-20$ & $8(8 \%)$ \\
$21-31$ & $25(25 \%)$ \\
$32-42$ & $38(38 \%)$ \\
$43-53$ & $23(23 \%)$ \\
$>54$ & $6(6 \%)$ \\
Polyp stage & \\
Stage 0 & $0(0 \%)$ \\
Stage 1 & $15(15 \%)$ \\
Stage 2 & $40(40 \%)$ \\
Stage 3 & $45(45 \%)$ \\
\hline
\end{tabular}


Table 2 Patient Characteristics based on Chronic Rhinosinusitis with Nasal Polyp Risk Factors

\begin{tabular}{lcc}
\hline \multirow{2}{*}{$\begin{array}{c}\text { Subject } \\
\text { Characteristics }\end{array}$} & $\begin{array}{c}\text { Male } \\
\text { Patients }\end{array}$ & $\begin{array}{c}\text { Female } \\
\text { Patients }\end{array}$ \\
\cline { 2 - 3 } Smoking habit & $23(41.1 \%)$ & $12(27.3 \%)$ \\
Iatrogenic & $1(1.8 \%)$ & $0(0 \%)$ \\
Allergy & $20(35.7 \%)$ & $18(40.9 \%)$ \\
Asthma & $14(25 \%)$ & $15(34.1 \%)$ \\
Aspirin & $0(0 \%)$ & $2(4.5 \%)$ \\
sensitivity & $0(0 \%)$ & $2(4.5 \%)$ \\
Genetic & $1(1.8 \%)$ & $2(4.5 \%)$ \\
Fungus &
\end{tabular}

The clinical diagnosis of CRS was made using the guideline by the RSTF of the American Academy of Otolaryngology, Head and Neck Surgery (AAO-HNS). ${ }^{8}$ The major criteria included asthma, allergic rhinitis, aspirin sensitivity, allergy, smoking habit, medical history, bacteria or virus. ${ }^{3-8}$

\section{Results}

A hundred patients diagnosed with CRS visited the Otolaryngology-Head and Neck Surgery outpatient clinic of Dr. Hasan Sadikin General Hospital. There were 56 males and 44 females, with a male to female ratio of 1.2:1. The age ranged from 10 years to $>54$ years.

The study showed that the number of male patients was higher than females (Table1). The data revealed that the majority of patients were 32-42 years old (38\%) followed by patients who were 21-31 years old(25\%). CRS with NP was rarely found in patients whose age was $>54$ years $(6 \%)$. Based on the Lund-Mackay system of staging, the majority of patients were in stage $3(45 \%)$ and stage 2 $(40 \%)$.
There were several risk factors found in male patients, including smoking 23 (41.1\%), allergy $20(35.7 \%)$, and asthma $14(25 \%)$ (Table 2). The risk factors found in female patients were allergy $18(40.9 \%)$, asthma 15 (34.1\%), and smoking habit 12 (27.3\%).

\section{Discussion}

In general population, the prevalence of NP in adults is around 1-4\%.3-6 The prevalence of $\mathrm{NP}$ in children is lower than adults, especially in cystic fibrosis. However, the frequency of NP is higher along with the increasing age until $>50$ years.

Chronic rhinosinusitis is commonly found in adults aged 32-42 years old (Table 1). This study shows a similar result to several studies which stated that CRS occurs in people aged 35-42 years old. ${ }^{8,13,14}$ However, a study has reported different results that CRS occurs in $>19$ years old patients while another study discovered CRS occurs in people aged 15-24 years old. ${ }^{4,9}$

Most CRS with NP patients who visited the Otolaryngology-Head and Neck Surgery clinic, Dr. Hasan Sadikin General Hospital, Bandung in 2014 were 32-42 years old with employees with outdoor activities who were exposed the air pollution, such as smoke and vehicle emission comprised the majority of the patients based on their occupation. This condition leads to the risk of virus and fungal infection.

The CRS with NP occurs in males (56\%) and females (44\%). Chronic rhinosinusitis with NP affects anyone in any age, as well as in adults aged $30-60$ years. ${ }^{9}$ In addition, the study also reported that NP affected men and women with a ratio of 1.42:1.

Chronic rhinosinusitis and NP is considered a disease. The lack of data and the presence of some contradictions create a challenge for conducting a study to differentiate CRS and NP. However, several studies also discovered that

Table 3 Total of Chronic Rhinosinusitis with Nasal Polyp Risk Factors

\begin{tabular}{lccc}
\hline \multicolumn{1}{c}{ Total Characteristics } & Total Patients (n=100) & Male Patients & Female Patients \\
\hline One risk factor & $90(90 \%)$ & $51(91 \%)$ & $39(89 \%)$ \\
Two risk factors & $9(9 \%)$ & $5(9 \%)$ & $4(9 \%)$ \\
More than two risk factors & $1(1 \%)$ & $0(0 \%)$ & $1(2 \%)$ \\
\hline
\end{tabular}


NP is regarded as a subchronic rhinosinusitis disorder, ${ }^{1,6-9}$

There are several studies on rhinosinusitis with NP conducted for any purpose. ${ }^{10-13}$ The studies revealed that rhinosinusitis with NP symptoms caused by the inflammatory cells, Th1/Th2 polarization, remodeling process and edema shaping or immune product. Therefore, these investigations do not carry sufficient results that only a small number of studies examined the risk factor of rhinosinusitis with NP.

Most patients in this study were on stage 3 . This result is similar to the result of a previous study that reported the majority of patients were on stage 3 which was $79.1 \%$ of the subjects $(n=43) \cdot{ }^{15}$ It was also stated that the higher nasal polyp stage led to complications, such as chronic obstructive lung disease (COPD). The higher nasal polyp stage is caused by the patient unawereness of the CRS with NP symptom.

The most frequently found CRS with NP risk factors are smoking habit and allergy for males and females, respectively. The allergy

\section{References}

1. Fokkens WJ, Lund VJ, Mullol J, Bachert C, Alobid I, Baroody F, Cohen N, et al. EPOS 2012: European position paper on rhinosinusitis and nasal polyps 2012. A summary for otorhinolaryngologists. Rhinology. 2012;50(1):1-12.

2. Bachert C, Pawakar Ruby, Zhang L, Bunnag C, Fokkens WJ, Hamilos DL, et al. Chronic Rhinosinusitis. WAO J. 2014;7(25):1-28.

3. Demirdag YY, Ramadan HH. Direct measurement of upper airway inflammation in children with chronic rhinosinusitis: implications for asthma. Curr Opin Allergy Clin Immunol. 2016;16(1):18-23.

4. Park DY, Lee EJ, Kim JH, Kim YS, Jung CM, Kim KS. Correlation between symptoms and objective findings may improve the symptombased diagnosis of chronicrhinosinusitis for primary care and epidemiological studies. BMJ Open. 2015;16;5(12):1-7.

5. Newton JR, Ah-See KW. A review of nasal polyposis. Ther Clin Risk Manag. 2008;4(2):507-12.

6. Bousquet J, Khaltaev N, Cruz AA, Denburg J, Fokkens WJ, Togias A, et al. Allergic rhinitis and its impact on asthma (ARIA) 2008. J Allergy prevalence in NP patients is $10-64 \%$.

A study reported that the upper airway functions as the first line of defense against inhaled toxins and pathogens including environmental pollutants like tobacco smoke and microbes that can cause potential harm to the host. ${ }^{16}$ The study also described that the sinonasal epithelial cells utilize the mucociliary clearance (MCC) which relies on an airway surface liquid (ASL) barrier and proper ciliary beating to effectively transport mucus and clear potentially toxic irritants.

In this study, it was found that number of male patients is higher than female patients for CRS with NP. The majority of patients are between 32-42 years old and have at least a risk factor, such as smoking habit in males and allergy in females.

This study has several limitations, including the sample size. Further studies on CRS may need to collect data from several hospitals to be able to achieve the appropriate sample size with adequate power. Knowledge on CRS characteristics is important for deciding treatment for patients.
Clin Immunol. 2008;6(Suppl 86):s8-160.

7. Gelardi M, Iannuzzi L, Taufuri S, Passalacqua G, Quaranta N. Allergic and non allergic rhinitis: relationship with nasal polyposis, asthma, and family history. Acta Otorhinolaringol Ital. 2014;34(1):36-41.

8. Fokkens WJ, Lund VJ, Mullol J, Bachert C, Alobid I, Baroody F, etal.EPOS 2012: European position paper on rhinosinusitis and nasal polyps 2012. A summary for otorhinolaryngologists. Rhinology. 2012;50(1):1-12.

9. Bernstein JM, Anon JB, Rontal M, Conroy J, Wang C, Sucheston L. Genetic polymorphisms in chronic hyperplastic sinusitis with nasal polyposis. Laryngoscope. 2009;119(7):125864.

10. Mangunkusumo E, Soetjipto D. Sinus paranasal dan sinusitis. 6th Ed. Jakarta: Balai Penerbit FK UI; 2009.

11. Lim M, Citardi MJ, Leong JL. Topical antimicrobials in the management of chronic rhinosinusitis: a systematic review. Am J Rhinol. 2008,22(4):381-9.

12. Lund VJ, Mackay IS. Staging in rhinosinusitus. Rhinology. 1993;31(4):183-4.

13. Chojnowska S, Kępka A, Waszkiewicz N, 
Kolodziejczyk ZP, Konarzewska-Duchnowska E, Ościłowicz K, et al. Etiopathogenesis of nasal polyps. Prog Health Sci. 2013;3(2):151-9.

14. Oakley GM, Curtin K, Orb Q, Schaefer C, Orlandi RR, Alt JA. Familial risk of chronic rhinosinusitis with and without nasal polyposis: genetics or environment. Int Forum Allergy Rhinol. 2015;5(4):276-82.

15. Hanis IF, Raharjo SP, Arfandy RB, Djufri
NI. Hubungan antara stadium polip nasi denganfungsi ventilasi dan drainase telinga tengah berdasarkan gambaran timpanogram. CDK. 2010;37(6):419-23.

16. Reh DD, Higgins TS, Smith TL. Impact of tobacco smoke on chronic rhinosinusitis: a review of the literature. Int Forum Allergy Rhinol. 2012;2(5):362-9. 